\title{
Male production by workers in the polygynous ant Prolasius advenus
}

\author{
J. Grangier · A. Avril · P. J. Lester
}

Received: 14 August 2012/Revised: 5 February 2013/Accepted: 7 February 2013

(C) International Union for the Study of Social Insects (IUSSI) 2013

\begin{abstract}
The ability of workers to produce male individuals is reported here for the first time in a species of the formicine ant genus Prolasius. We show that Prolasius advenus workers possess ovaries and demonstrate that they are able to produce adult males in queenless colonies. We also experimentally tested the influence of queen volatiles on the level of worker reproduction. Workers produced fewer eggs in treatments where they could perceive odors from queens. Some volatile compounds emitted by queens may thus have a signaling or inhibitory effect on worker reproduction. This effect of queen presence did not entirely stop worker reproduction, however, as adult males still emerged under these conditions. Worker-produced males were absent only in treatments with the physical presence of queens. Dissections of workers collected from queenright nests in the field revealed signs of egg-laying activity in more than half of individuals. Together, these results suggest that in nature $P$. advenus workers produce males at least in orphaned colonies or in situations where the physical presence of queens is limited.
\end{abstract}

Keywords Worker reproduction - Ant males .

Prolasius advenus $\cdot$ Reproductive conflicts

\section{Introduction}

Male production can be an important source of conflict within ant colonies. Workers typically lack the ability to

J. Grangier ( $₫)$ · A. Avril · P. J. Lester

Centre for Biodiversity and Restoration Ecology,

School of Biological Sciences, Victoria University of Wellington,

PO Box 600, Wellington, New Zealand

e-mail: grangier.ju@gmail.com mate and thus, cannot produce diploid, female-destined brood. In many species, however, workers may possess functional ovaries and can lay unfertilized eggs. Such eggs may not be viable and serve instead as a form of food storage (i.e., trophic eggs), but these eggs may also be viable and develop into haploid, adult males (Hölldobler and Wilson, 1990). The possibility for workers to rear their own sons to the detriment of the queen's offspring has the potential to create conflict among nestmates over male parentage, with important ecological and evolutionary consequences (Bourke, 1988). Therefore, male production by workers is thought to depend not only on their own physiological ability but potentially also on the information from or control by other members within the colony. For example, queen pheromones are thought to act as a signal inducing workers to self-restrain their reproductive activity in Lasius niger (Holman et al., 2010). In other situations, nestmate workers can be aggressive toward the reproductive individuals or their eggs (worker-policing; e.g., Brunner and Heinze, 2009), and queens may even physically destroy the worker brood (queen-policing; e.g., Smith et al., 2011).

The origin and functioning of policing is still debated, including the influence of colony growth stage (Ohtsuki and Tsuji, 2009) and the relative importance of relatedness amongst nestmates and colony-level costs associated with worker reproduction (Hammond and Keller, 2004; Wenseleers and Ratnieks, 2006). Another important issue is the nature of the cues influencing worker reproduction as well as the role of such cues as control mechanisms or as honest signals from queens (Keller and Nonacs, 1993; Monnin, 2006; Heinze and D'Ettorre, 2009; van Zweden, 2010; Brunner et al., 2011).

Although a recent extensive review on the topic is lacking, Bourke (1988) reported worker-produced males in approximately 50 species from 24 genera based on 
published data. Comparatively, more than 12,500 ant species in about 300 genera have been described to date. Worker reproduction thus appears under-reported, which can bias the interpretations of patterns observed at a wide taxonomic scale. For example, this could partially explain why large comparative analyses have resulted in contrasting conclusions when testing theories about worker reproduction and policing in social insects (Hammond and Keller, 2004; Wenseleers and Ratnieks, 2006). Testing for worker reproduction in additional species is, therefore, a relevant approach to answer questions related to worker-produced males.

In this study, worker reproduction is reported for the first time, to our knowledge, in the formicine genus Prolasius. The small brown bush ant Prolasius advenus (Fr. Smith) 1862 is a common endemic species in New Zealand and the most conspicuous and dominant ant species in Nothofagus beech forests (Don, 2007; Grangier and Lester, 2011). Despite its prominence in these native ecosystems, the biology of this ant species remains relatively unknown, like that of the 18 other congeneric species (Shattuck, 1999). Based on preliminary observations suggesting that egg production occurred in queenless $P$. advenus colonies, we conducted an experimental study specifically addressing the following questions: (1) Can P. advenus workers produce viable offspring? (2) What is the anatomy of their reproductive system and do all workers possess ovaries? (3) Does queen odor restrict reproduction in workers? (4) Do ant workers recently collected from queenright nests in their native habitat also present signs of reproductive activity?

\section{Materials and methods}

In February and March 2010, ten P. advenus colonies were collected in beech forests located in the Nelson Lakes National Park $\left(41^{\circ} 49^{\prime} 59 \mathrm{~S}, 172^{\circ} 50^{\prime} 58 \mathrm{E}\right)$ and in the Maitai Valley $\left(41^{\circ} 18^{\prime} 21 \mathrm{~S}, 173^{\circ} 22^{\prime} 16 \mathrm{E}\right)$, in the South Island of New Zealand. All colonies were polygynous, containing up to 48 queens. In the laboratory, each colony was divided into three experimental treatments of standardized sizes. One experimental treatment was constituted of 400 workers and 6 queens (treatment A) and the two other treatments were constituted of 200 workers only (treatment types B and C). There were two exceptions due to limited total colony sizes: one replicate nest in treatment A contained only 250 workers instead of 400 , and another replicate nest in treatment A contained only 4 queens instead of 6 . Males and brood, including eggs, were avoided while forming the colonies, and their absence was carefully checked. In total, 30 experimental colonies ( 10 for treatment A, 10 for B and 10 for $\mathrm{C}$ ) were housed in plaster nests with humidification provided by a water tank.
Plaster nests were designed in such a way that colonies in treatments A and B lived in two compartments of a same nest separated by a metallic double-mesh, allowing odors to circulate but preventing any physical contact between members of the two groups. Colonies in treatment $\mathrm{C}$ lived in independent nests (Fig. 1). Nesting space for colonies in treatment A was twice that available for those in treatments $\mathrm{B}$ and C. Each ant colony had access to its own foraging arena, where mealworms and $20 \%$ honey/water solution were offered three times a week. Foraging arenas were covered by mesh to prevent all possibilities for future winged individuals to escape.

We had four goals in this project. First, to confirm that workers can produce eggs and to determine if worker-produced eggs do develop into viable adult individuals, brood production in all nests of treatments $\mathrm{B}$ and $\mathrm{C}$ was checked regularly, starting about 1 month after nest installation in May 2010 and finishing in March 2011 (17 census sessions in total). Without opening the nests, all sections of the plaster nests were visually inspected through the glass covering the plaster using a magnifying glass or a stereomicroscope when necessary. Eggs, larvae, pupae and adult males were counted. Although brood produced by queens and workers could not be distinguished in treatment $\mathrm{A}$, these nests were monitored in the same way as in treatments B and $\mathrm{C}$ to monitor the overall reproductive activity and the production of males in these conditions.

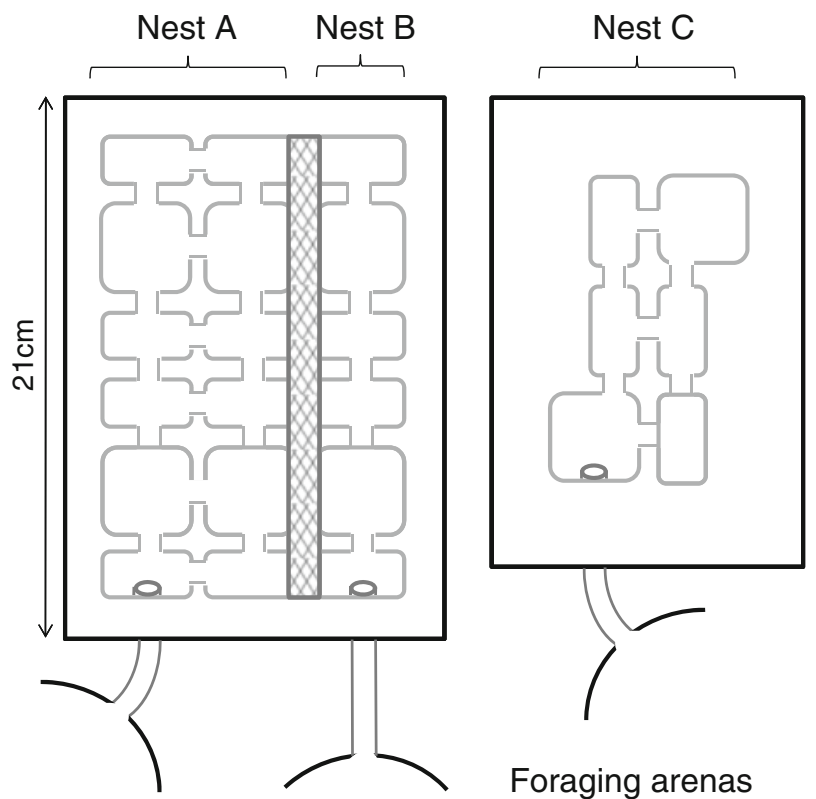

Fig. 1 Schematic representation of the three types of nests in the three experimental treatments: $A$ Six queens and 400 workers, $B-C 200$ workers and no queens. The hatched rectangle represents a dual layer of the mesh preventing physical contact between ants of compartments $A$ and $B$. Each nest was connected to its own foraging arena 
Second, dissections were used to describe the reproductive system in $P$. advenus workers and to determine whether reproductive organs were present and active in individual worker ants. From each of the 20 queenless nests (treatments B and C), five workers (six in one case) were killed and their gasters dissected to evaluate their ovarian activity at the end of the experiment, in April and May 2011. Worker length is generally between 2 and $2.5 \mathrm{~mm}$. Dissections were undertaken in water using a stereomicroscope at 50-100× magnification. The presence of oocytes was verified, as well as the presence of yellow bodies which were recorded as absent, light-colored or dark-colored. Yellow bodies are remnants of follicular tissue and indicate that the individual has previously oviposited, with a relatively darker color suggesting a recent and frequent activity (Peeters et al., 2000). For one worker per nest, the length of ovarioles was also measured and standardized by the length of the first gaster segment. In addition, six $P$. advenus queens were dissected to characterize the anatomical differences between queens and workers reproductive system in this species.

Third, to determine if queen odor can inhibit worker reproduction, we compared the quantity of brood and the level of ovarian activity recorded in workers from treatment B (which were exposed to queen odor) with those recorded in workers from treatment $\mathrm{C}$ (which were totally isolated from queens). Regarding brood quantity, only eggs were produced in sufficient number for their amounts to be compared statistically. We used a paired $t$ test to compare the peak number of eggs in treatments B and C. As for the anatomical parameters, the percentage of ants possessing oocytes and yellow bodies were calculated for each nest. The average percentage, as well as the average ovariole length, was compared between treatments using paired $t$ tests and Wilcoxon signed-rank tests. Paired tests were used because nests in treatments $\mathrm{B}$ and $\mathrm{C}$ were each time sampled from the same colony. A posteriori power analyses were performed using the program $\mathrm{G}^{*}$ Power 3 (Faul et al., 2007) to evaluate the probability of making a Type II error in cases of non-significant differences. We also calculated Cohen's $d_{z}$ statistic, which is used as a standardized effect size index.

Finally, to investigate the existence of ovarian activity in workers under natural conditions, individuals from four queenright colonies were collected in the field in May 2010. Three nests came from the two sites where we collected colonies for experimental use (Nelson Lakes National Park and Maitai Valley), and one from the Pelorus Bridge area, South Island of New Zealand $\left(41^{\circ} 17^{\prime} 53 \mathrm{~S}, 173^{\circ} 34^{\prime} 18 \mathrm{E}\right)$. Five to nine workers per nest (28 in total) were dissected as described above, shortly after collection (between 1 and 3 weeks). Workers were kept with at least one queen between their collection in the field and the dissection. The presence of oocytes and of yellow bodies was recorded.

\section{Results and discussion}

The primary result of our study is that $P$. advenus workers can produce male offspring. In experimental queenless colonies, workers were observed to lay eggs relatively quickly after queen removal. Fifty percent of colonies had produced eggs approximately 2 months after their separation from the mother-colony, and all the colonies had worker-produced eggs by the end of the experimental period (treatments B and C combined). Some eggs developed into larvae and pupae, and adult males emerged 7 months after the start of the experiment. In total, the 20 worker-only nests produced at least 37 males over the experimental period (sum of maximum numbers of males recorded during a single counting session in each nest, treatments B and C combined).

All workers from treatments B and C that were dissected $(N=101)$ possessed a pair of ovaries each formed of a single ovariole (Fig. 2a). This result clarifies the anatomy of $P$. advenus workers as previous work regarding their reproductive system based on anatomical sections was inconclusive (Smith, 1969). We found no spermatheca in these workers, indicating that they cannot mate, which is the case for workers of most of ant species. Queens possess a spermatheca and substantially more developed ovaries with approximately 10 ovarioles each (Fig. 2b).

All colonies from treatments $\mathrm{B}$ and $\mathrm{C}$ produced eggs with similar temporal variation in the number of eggs present within each nest (Fig. 3a). The average maximum number of eggs was observed in October in both treatments, but was significantly higher in treatments without exposure to queen odors relative to those in contact with their odors (paired $t$ test: $t=2.6, \mathrm{df}=9, P=0.028$ ). Eggs did not all develop into larvae. In treatment $\mathrm{B}$, larvae, pupae and adult males were produced in four, three and three colonies, respectively. In treatment $\mathrm{C}$, they were produced in seven, four and two colonies, respectively. The average number of larvae, pupae and adult males, when present, were similar in both treatments (Fig. 3b-d). The highest number of males observed at any one time was five, three and two in three colonies of the treatment $\mathrm{B}$, and 26 and one in two colonies of the treatment $\mathrm{C}$. These maximum numbers of males were all reached at the same period in the five colonies, in January 2011. Despite of the controlled and constant conditions in which the experiment was performed within a laboratory, this timing within the southern hemisphere summer seems to match the production of alate individuals in the field (pers. obs.). 

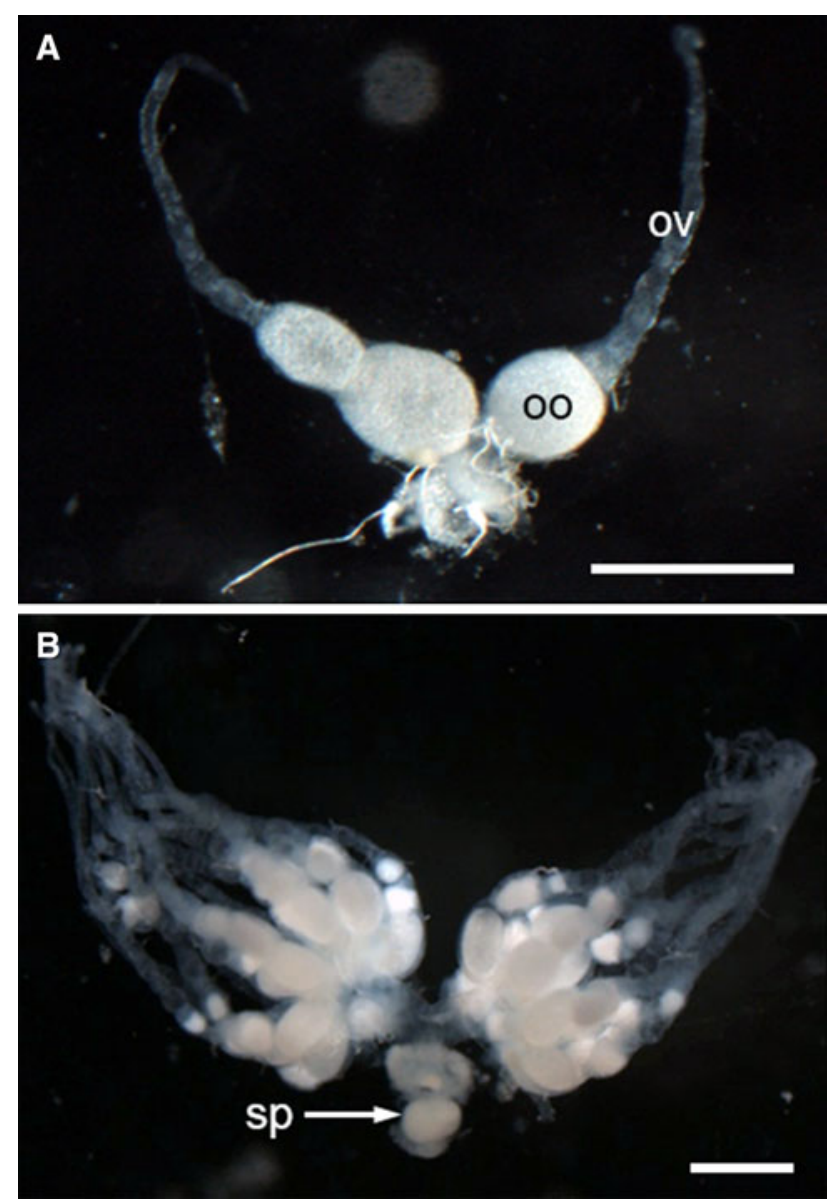

Fig. 2 Pictures of the reproductive systems of $P$. advenus workers (a) and queens (b). In workers, a single ovariole (ov) per ovary is always present. In queens, there are about 10 ovarioles per ovary, and a spermatheca $(s p)$ is present. In both cases, several oocytes $(o o)$ can be seen. Scale bars $=0.5 \mathrm{~mm}$

Dark-yellow bodies suggested recent egg-laying activity in about half of the workers in both treatments B and C (Fig. 4). This result likely indicated that many workers in each nest contributed to the egg production. In line with the observed number of eggs in the two treatments, ovarian activity tended to be slightly more frequent in workers completely isolated from queens and their potential odors (Fig. 4). However, this trend was not statistically significant, with yellow bodies being present in $84.0 \pm 4.0$ and $92.7 \pm 3.9 \%$ of workers, in treatments $\mathrm{B}$ and $\mathrm{C}$, respectively (Wilcoxon signed-rank test: $W=-13, P=0.125$ ). Similarly, the percentage of workers whose ovarioles contained oocytes was $18.0 \pm 9.1$ and $28.5 \pm 6.8 \%$ in treatments $\mathrm{B}$ and $\mathrm{C}$, respectively (Wilcoxon signed-rank test: $W=-10, P=0.313$ ). The ratio between the length of the ovariole and first gaster segment was also not statistically different between treatments $\mathrm{B}$ and $\mathrm{C}(2.05 \pm 0.21$ and $2.37 \pm 0.23$, paired $t$ test: $t=0.58$, $\mathrm{df}=7, P=$ 0.578). The non-significance of these three latter tests
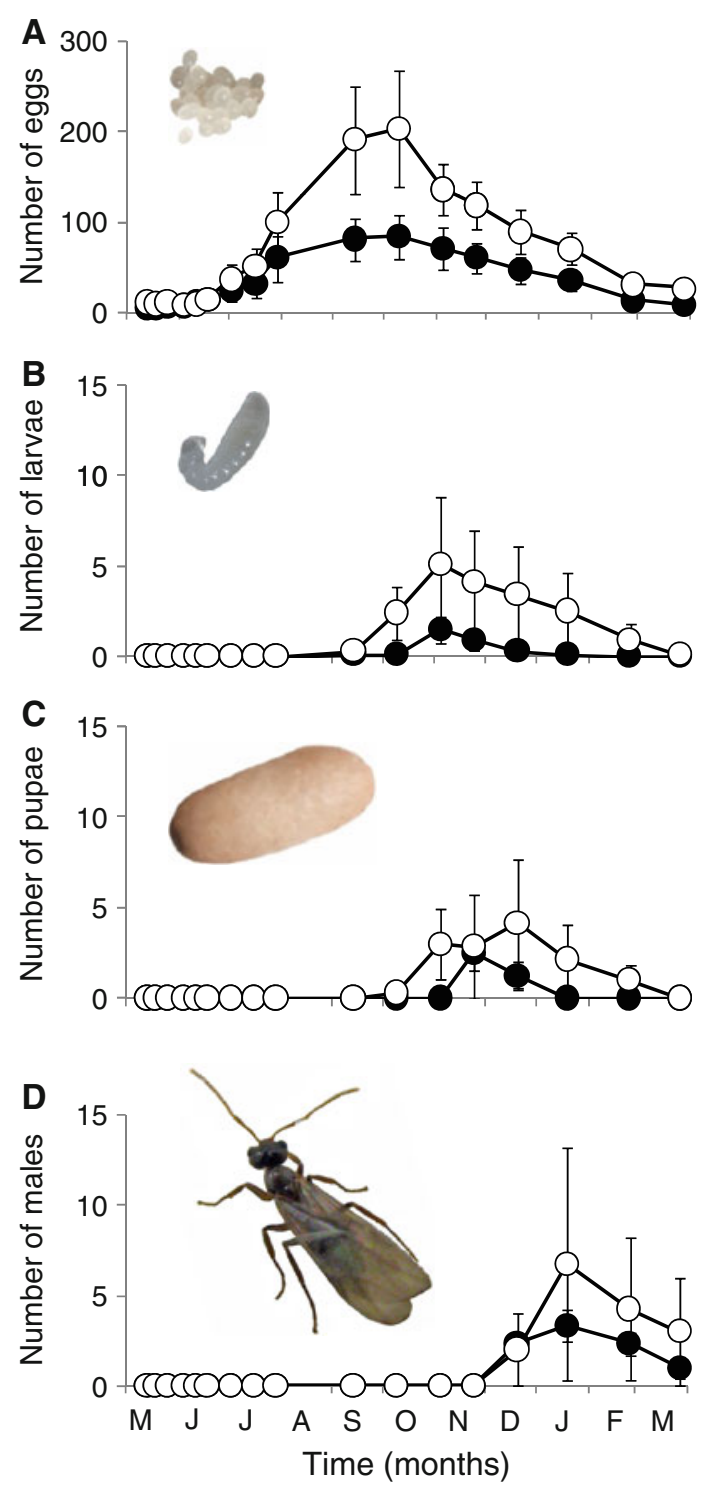

Fig. 3 The mean number of eggs (a), larvae (b), pupae (c) and adult males (d) present between May 2010 and March 2011 in experimental queenless colonies that were either within the range of queens' odor (treatment B, black dots) or totally isolated from queens (treatment C, white dots). The number of colonies was $N=10$ in (a). The number of colonies used to calculate the mean production of larvae, pupae and adult males was the number of colonies that had produced some individuals of the previous developmental stage, at each time stage. In $\mathbf{b}, \mathbf{c}, \mathbf{d}$, the number of colonies was $N=10,4$ and 3 and $N=10,7$ and 4 in treatments B and C, respectively. Note the different scale for $y$-axis in a. Error bars indicate \pm 1 SE. Inset pictures illustrate each developing stage; all of which are at the same scale (cocoon length is $3 \mathrm{~mm}$ )

regarding ovarian activity, however, should be considered cautiously. A post hoc power analysis indicated that our ability to detect differences based on 10 nests per treatment was low (actual power $<0.5$ in all cases). Effect sizes were small to medium (Cohen's $d_{z}$ was $0.16,0.32$ and 0.57 for the ovariole length, presence of oocytes and presence of yellow 


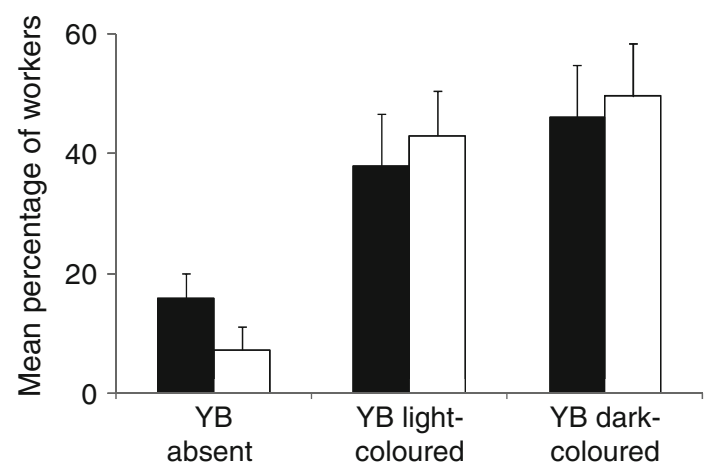

Fig. 4 Mean $( \pm 1 \mathrm{SE})$ percentage of workers per nest whose yellow bodies $(Y B)$ are absent, light-colored or dark-colored, in experimental treatments B (black bars) and C (white bars). $N=10$ nests in each case, and $n=5-6$ workers per nest

bodies, respectively). They may have biological significance with all physiological parameters pointing towards an increased ovarian activity in workers totally isolated from queens. This result would thus merit further work with increased sample sizes. Together, our results indicate that queen volatiles may have had a signaling or inhibitory effect lowering worker egg-laying, but did not prevent worker reproduction entirely.

What can be inferred from these results regarding worker reproduction in natural conditions? Clearly they suggest that orphaned colonies, as mimicked by experimental treatment $\mathrm{C}$, are likely to produce males, as it is the case in other ant species (Hölldobler and Wilson, 1990). Whether and how this worker reproduction occurs in natural queenright nests is more complex to determine. On the one hand, queens used in treatment A presented an extremely low level of reproduction: we identified freshly emerged workers in only one replicate colony of this treatment. Although the monthly monitoring in the treatment with both queens and workers together was certainly not enough to detect all callow workers and thus probably underestimated the real queen reproduction, this result clearly indicated low reproductive activity in queens. This result may be due to a number of parameters related to their captivity, and the same has been observed in almost all $P$. advenus colonies that we have reared so far in the laboratory (pers. obs.). As a result, we cannot exclude the possibility that more active queens, like those under natural conditions, may have conducted to different results in the adjacent workers of treatment B. However, no males were produced in treatment $\mathrm{A}$ and eggs were less numerous in treatment $\mathrm{B}$ relative to $\mathrm{C}$. These results suggest that queens with even low reproductive activity may reduce worker reproduction. Possible, nonexclusive explanations are that workers refrained from laying eggs in the presence of queens (self-policing), or workers destroyed the eggs of other workers more intensively when queens are present (worker-policing), or that queens mechanically destroyed worker-produced brood (queen-policing). Queen volatiles appeared to influence the levels of self-policing and/or worker-policing as eggs were less abundant in treatment B compared with C. Ultimately, however, adult males emerged in these two treatments and not in treatment A. Worker reproduction thus appeared to be more strongly influenced by the queens when the two female castes were in close physical contact. This conclusion adds to the growing evidence that physical contact is crucial for queens or their brood to influence the reproductive activity of their nestmates, whether those are workers (Tsuji et al., 1999; Endler et al., 2004; Holman et al., 2010) or other queens (Coston et al., 2011). Thus, while the level of worker reproduction in treatment B is to be interpreted cautiously, it may actually reveal that $P$. advenus workers lay eggs even in queenright nests but that full brood development is only possible in nest chambers that are far enough from or not accessible by queens (as mimicked by treatment B).

Results and observations from ants in the field, or shortly after collection, support the hypothesis that $P$. advenus workers attempt to reproduce in queenright nests. First, $P$. advenus typically nest in the soil or rotten logs. These nests are large and formed of a complex network of galleries and chambers. Such nest features make worker isolation from queens plausible for workers even in queenright colonies. Second, we found that workers from queenright nests also show signs of egg-laying activity. Yellow bodies were present in $68.1 \pm 5.3 \%$ of workers dissected shortly after their collection in the field from queenright colonies (28 workers from four nests). This value is inferior to those found in the experimental queenless treatments $\mathrm{B}$ and $\mathrm{C}$ $(84.0 \pm 4.0$ and $92.7 \pm 3.9 \%$, respectively), but it still represents a high proportion of the workers. Oocytes were present in $69.4 \pm 14.4 \%$ of workers from these field queenright nests. It is not clear, however, whether this egglaying activity is a production of reproductive or trophic eggs. Despite repeated observations of both oocytes and laid eggs, we did not find clear, reliable morphological signs to conclusively determine if reproductive and trophic eggs are both produced or in what proportion. Moreover, yellow bodies are absent from trophic eggs layers in some species (Gobin et al., 1999) but present in others (Dietemann et al., 2002). Further studies are thus necessary to elucidate the exact nature of the egg-laying activity in workers of $P$. advenus queenright nests.

To conclude, our study demonstrates that $P$. advenus workers can produce viable males and suggests that it may happen under natural conditions, at least in orphaned colonies and possibly even in large queenright nests. Further studies focusing on these different scenarios are now necessary to assess the importance of workers in the total male production in $P$. advenus. In particular, molecular tools will 
be determinant in clarifying the end product of workerproduced oocytes, the origin of males in natural nests, and the colony kin structure and mating system in this species.

Acknowledgments We are grateful to Evan Brenton-Rule for lab assistance, to Allan Burne, Monica Gruber and Alexandra Sébastien for useful discussions, to two anonymous reviewers for useful comments on the manuscript, and to the Department of Conservation of New Zealand for allowing us to work in the Nelson Lakes National Park. This work was supported by a RSNZ Marsden fund grant.

\section{References}

Bourke A.F.G.1988. Worker reproduction in the higher eusocial Hymenoptera. Q. Rev. Biol. 63: 291-311

Brunner E. and Heinze J. 2009. Worker dominance and policing in the ant Temnothorax unifasciatus. Insect. Soc. 56: 397-404

Brunner E., Kroiss J., Trindl A. and Heinze J. 2011. Queen pheromones in Temnothorax ants: control or honest signal? BMC Evol. Biol. 11: 55

Coston D.J., Gill R.J. and Hammond R.L. 2011. No evidence of volatile chemicals regulating reproduction in a multiple queen ant. Naturwissenschaften 98: 625-629

Dietemann V., Hölldobler B. and Peeters C. 2002.Caste specialization and differentiation in reproductive potential in the phylogenetically primitive ant Myrmecia gulosa. Insect. Soc. 49: 289-298

Don W. 2007. Ants of New Zealand. Otago University Press, Dunedin, New Zealand.

Endler A., Liebig J., Schmitt T., Parker J.E., Jones G.R., Schreier P. and Hölldobler B. 2004. Surface hydrocarbons of queen eggs regulate worker reproduction in a social insect. Proc. Natl Acad. Sci. USA 101: 2945-2950

Faul F., Erdfelder E., Lang A.-G. and Buchner A. 2007. G*Power 3: A flexible statistical power analysis program for the social, behavioral, and biomedical sciences. Behav. Res. Meth. 39: 175-191

Gobin B., Billen J. and Peeters C. 1999. Policing behaviour towards virgin egg layers in a polygynous ponerine ant. Anim. Behav. 58: $1117-1122$
Grangier J. and Lester PJ. 2011. A novel interference behaviour: invasive wasps remove ants from resources and drop them from a height. Biol. Lett. 7: 664-667

Hammond R.L. and Keller L. 2004.Conflict over male parentage in social insects. PLOS Biology 2: 1472-1482

Heinze J. and d'Ettorre P. 2009. Honest and dishonest communication in social Hymenoptera. J. Exp. Biol. 212: 1775-1779

Hölldobler B. and Wilson E.O. 1990. The Ants. The Belknap Press of Harvard University Press, Cambridge, Massachusetts.

Holman L., Jørgensen C.G., Nielsen J. and d'Ettorre P. 2010. Identification of an ant queen pheromone regulating worker sterility. Proc. R. Soc. Lond. B 277: 3793-3800

Keller L. and Nonacs P. 1993. The role of queen pheromones in social insects: queen control or queen signal? Anim. Behav. 45: 787-794

Monnin T. 2006. Chemical recognition of reproductive status in social insects. Ann. Zool. Fennici 43: 515-530

Ohtsuki H. and Tsuji K. 2009. Adaptive reproduction schedule as a cause of worker policing in social Hymenoptera: a dynamic game analysis. Am. Nat. 173: 747-758

Peeters C., Liebig J. and Hölldobler B. 2000. Sexual reproduction by both queens and workers in the ponerine ant Harpegnathos saltator. Insect. Soc. 47: 325-332

Smith A.A., Hölldobler B. and Liebig J. 2011.Reclaiming the crown: queen to worker conflict over reproduction in Aphaenogaster cockerelli. Naturwissenschaften 3: 237-240

Smith C.E. 1969. A morphological and behavioural study of the ants Amblyopone saundersi Forel and Prolasius advena Fr. Smith (Hymenoptera: Formicidae). Unpublished BSc(Hons) thesis, University of Otago, Dunedin

Shattuck S.O. 1999. Australian Ants: Their Biology and Identification. Monographs in Invertebrate Taxonomy. Volume 3

Tsuji K., Egashira K. and Hölldobler B. 1999. Regulation of worker reproduction by direct physical contact in the ant Diacamma sp. from Japan. Anim. Behav. 58: 337-343

Van Zweden J.S. 2010. The evolution of honest queen pheromones in insect societies. Commun. Integr. Biol. 3: 50-52

Wenseleers T. and Ratnieks F.L.W. 2006. Comparative analysis of worker reproduction and policing in eusocial Hymenoptera supports relatedness theory. Am. Nat. 168: 163-179 